http://dx.doi.org/10.18675/1981-8106.vol26.n51.p183-190

\title{
Em forma de Resenha: Mergulho em "Armadilhas da Sedução: os Romances de M. Delly"
}

CUNHA, Maria Teresa Santos. Armadilhas da sedução: os romances de M. Delly. Belo Horizonte: Autêntica, 1999.

\section{Eliane Aparecida Bacocina'}

Carolina Gonçalves Souza"

Marilena Aparecida Jorge Guedes de Camargo"II

'UNESP - Universidade Estadual Paulista - "Júlio de Mesquita Filho" - Câmpus de Rio Claro, São

Paulo - Brasil. E-mail: elianeab3@gmail.com

"' 'UNESP - Universidade Estadual Paulista - "Júlio de Mesquita Filho" - Câmpus de Rio Claro, São Paulo - Brasil. E-mail: pedagogacarol@yahoo.com.br

III ' UNESP - Universidade Estadual Paulista - "Júlio de Mesquita Filho" - Câmpus de Rio Claro, São Paulo - Brasil. E-mail: marilena@linkway.com.br

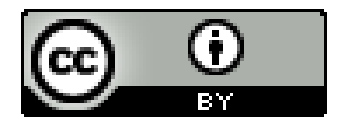

Educação: teoria e prática, Rio Claro, SP, Brasil - eISSN: 1981-8106

Está licenciada sob Licença Creative Common

\section{Introdução}

A obra é de Maria Teresa Santos Cunha, doutora em Educação pela USP e professora da Universidade do Estado de Santa Catarina - UDESC. Este livro é fruto de sua tese de Doutorado e apresenta uma contribuição para os estudantes que focam seu trabalho em práticas de leitura e história da educação brasileira, como possibilidade de pesquisa.

A autora inicia seu trabalho apresentando os caminhos de sua pesquisa sobre os romances. M. Delly é o pseudônimo de dois irmãos, Frédérick Henri e Jeanne-Marie Petitjean de La Rosiére, que viveram no final do século XIX e metade do século XX. Editados no Brasil pela Companhia Editora Nacional entre os anos 30 e 60, os romances seguiam quase sempre a mesma estrutura: a moça pobre encontra um rapaz rico, com o qual se casa ao final. 
As motivações para esta pesquisa são várias, e uma delas diz respeito à sua trajetória de leituras: estes livros fizeram parte da adolescência da autora e hoje, criticamente, explicita a forma como estas leituras foram "incentivadas" e contribuíram para a formação de subjetividades.

Apontando para a popularidade destes livros entre as mulheres leitoras, a autora se aproximou do objeto de estudo por meio de questionamentos iniciais em relação às obras, quanto ao gosto pela leitura, atributos estéticos dos livros (capas apelativas), dentre outros. Os livros, de modo geral, apresentavam uma certa forma de educação feminina, descrevendo condutas, normas e valores vigentes entre mulheres.

Primeiramente, foi feita a leitura e fichamento dos romances, seguida da criação de categorias para iniciar uma análise. Essa análise, feita na perspectiva da História Cultural, referenciada por Chartier e Darnton quanto às capas, títulos, disposições tipográficas etc., foi aliada a outras leituras sobre a educação e a mulher, além de outras obras da literatura universal para auxiliar seu construto sobre a educação de sensibilidades femininas pela leitura.

Complementarmente, foram colhidos testemunhos pessoais de "seis mulheres professoras, brancas, de classe média e idades entre 48 e 66 anos" (CUNHA, 1999, p. 19), caracterizando bem o público leitor destas obras analisadas. Nessas entrevistas, emoções foram revividas pelas lembranças das leituras, misturando-se às emoções da própria pesquisadora, também leitora destes romances.

O clima nostálgico das entrevistas foi visto, pela pesquisadora, como compreensível, dado que rememorava a uma certa época de suas juventudes e que, à distância, o passado parece "mais ordenado" do que o presente.

Na perspectiva da História Cultural, os romances de M. Delly podem ser considerados "documentos" para o estudo de uma história da educação feminina. Cunha (1999) opta por apresentar sua pesquisa de forma narrativa, porque esse modo lança "luzes" ao tema que carece de conceitos e elaborações teóricas e desse modo o narrar pode historicizar conceitos, mas também porque a narrativa permite "um diálogo de múltiplas vozes que nos impele a percorrer vários caminhos" (p. 22). Percurso arriscado, como acrescenta a autora, mas aceito como possibilidade de pesquisa.

\section{Ler romances: fugir um pouco desse mundo}

O capítulo inicia-se com o depoimento de uma das mulheres entrevistadas, falando sobre a imaginação e a viagem de pensamento que lhe é proporcionada pelos momentos de leitura de romances, para introduzir a discussão sobre a associação mulher / romance presente no imaginário ocidental. Tal associação surge associada ao Romantismo (séc. XVIII), com sua dimensão sentimental e tendo maior repercussão na França do séc. XIX, com Stendhal no romance "O vermelho e o negro" e leitora Emma Bovary, personagem de Flaubert. São 
romances que apresentam como protagonistas mulheres leitoras de romances e vivem do entusiasmo que os mesmos lhes proporcionam e acabam por criar na sociedade o hábito da leitura enquanto dispositivo para combater o ócio feminino. No Brasil, a consolidação do hábito de ler romances pelas mulheres mais abastadas e alfabetizadas é influenciada pelo contato econômico, político e cultural com a França e outros países europeus, bem como pelo acesso a novas condições materiais, além de ser reforçada pelos princípios da educação da mulher de elite e do modelo feminino que se pretendia construir e reforçar, principalmente, pela Igreja Católica.

Enfatiza também: os atributos vistos como femininos, tais como a compostura, a polidez, a elegância, aliados à submissão, à prática de leitura em voz alta nos espaços domésticos, que provocava emoção, cenas de lágrimas e suspiros coletivos. O sucesso dos romances de folhetim do séc. XIX teve como consequência a crítica dos mesmos pela Igreja Católica, que passou a incentivar a leitura dos "romances honestos" e a repudiar os "romances imorais". Nesse contexto, os livros de M. Delly foram editados na França, a partir de 1910 e no Brasil a partir de 1935.

A ideia do conto de fadas no qual a heroína, órfã ou "enjeitada" se casa com o herói, aristocrata e rico, conquistado com suas virtudes e bons sentimentos, aliada a descrições de paisagens e cenários atingíveis apenas pela fantasia, encantou as leitoras de Florianópolis nos anos entre 1950 e 1960, que relatam as emoções e as lágrimas, os belos vestidos que ditavam a moda da época, a espera pelo final feliz no qual a mocinha sofredora se casaria com o rico aristocrata são indícios que evidenciam a necessidade de uma literatura de evasão, que permita "fugir" da realidade.

\section{Em Primeiras Cerimônias de Apropriação de Capas, de Títulos, de Letras}

É iniciado com a citação de alguns excertos de jornais e revistas que retratam a apropriação dos livros por alguns leitores, apropriação que pode ser de maneira atrativa ou repulsiva, dependendo do modo como o objeto se apresenta. No caso dos romances em questão, teve-se como objetivo analisar as estratégias de leitura e também o modo como alguns dispositivos favoreciam uma educação feminina, sensível e romântica, inicialmente por meio das capas, que já selecionavam o seu público-alvo.

Aponta-se o caráter apelativo das capas como um fator necessário em um país, como o Brasil, que não tem o hábito da leitura. A "embalagem” dos romances de M. Delly cumpriu com os seus objetivos: estabelecer uma relação direta com o conteúdo do livro e aumentar o público leitor, por meio de sua primeira impressão nas leitoras.

Continuando a análise, descreve-se uma propaganda de jornal de 1935 sobre sete obras de M. Delly como "a melhor" indicação de leitura para moças seguida de seus respectivos 
preços, variados, indicando os diferentes tipos de encadernações. Supõe Maria Teresa que essas diferenças de valores e encadernações favoreciam o acesso de leitoras de diferentes classes sociais.

A discussão sobre a "recepção" destas obras continua: embora Maria Teresa concorde que os romances de M. Delly contribuíram para a formação de subjetividades, sensibilidades e construir a mulher romântica e sonhadora, também compartilha das ideias de Chartier sobre a leitura como prática criadora (e não somente como prática marcada pelo autor e pelo editor): estas leituras também tinham um movimento contrário, de negação aos comportamentos e valores naquelas obras veiculadas. Exemplos dados pela autora sobre estas várias leituras (e não somente à incutida pelas obras de M. Delly), para se evitar o "consenso de época", são os depoimentos das participantes da pesquisa, que afirmam a existência dessa influência, mas também liam outros tipos de textos.

A leitura das capas também sugere uma educação pelas imagens: ao analisar a capa de Magali, alguns elementos remetem a um romantismo e o culto à natureza. O banco, os botões de flores, as vestes vaporosas das personagens dando uma ideia de inocência, além das descrições das mãos, suaves, sempre "ocupadas":

Nas estórias as mãos são "delicadas, finas, tais como pétalas de rosas, macias, têm dedinhos afusados, são mãos de fada": uma dimensão quase sagrada! Mãos sempre ocupadas (para não perturbar o corpo?) têm também o seu avesso: são "frementes; nervosas; ardentes; irrequietas". Suaves ou calejadas, tarefeiras ou preguiçosas, cruzadas ou soltas, além de educadas, as mãos educam, exprimem e traem as disposições da alma - leitoras e personagens, enfim, ligadas por um corpo comum e uma natureza orgânica comum (ibidem, p. 60).

O encanto por toda essa suavidade nos livros é descrito por uma de suas entrevistadas. As capas dos romances "Freirinha", "Corações inimigos" e "O fim de uma Valquíria" seguem esta mesma linha de suavidade. Já a capa de "Mitsi" (bem diferente das anteriores) é relembrada pelas entrevistadas como um exemplo de mulher forte, decidida, de fibra.

Mesmo após 1985, quando a Companhia Editora Nacional decide padronizar as capas destas obras, as novas conservaram esse caráter de suavidade, mostrando a mulher de atitude romântica e de espera passiva.

O sucesso de divulgação destas obras pode ter se dado devido às duas grandes instituições que os incentivaram: a família e a escola. A circulação foi grande, o que favoreceu a disseminação de comportamentos femininos socialmente aceitos. 


\section{Instruções para educar. Instruções para seduzir}

Neste capítulo o foco é contrastar a "educação que seduz" e a "sedução que educa" e analisar quais os sentidos das normas e valores tecidos nos romances de M. Delly. De que modo a heroína dos romances, com sua "pele nacarada, tez aveludada, andar gracioso, cabelos sedosos e macios" projetava uma conduta desejada, um padrão de beleza e moldava as leitoras em busca desse ideal? As mocinhas eram castas, doces, estremeciam, ruborizavam, tinham passos curtos. Já as vilãs eram desprovidas de beleza.

Algumas entrevistadas consideram esses personagens irreais, mas reconhecem que eles, em determinado momentos de suas vidas, alimentaram sonhos. Dentre as ideias disseminadas pelos romances, temos que a política era coisa para homens. As mulheres eram frágeis, seu espaço era o lar, sua vocação, o casamento e a maternidade, suas principais ocupações, bordar e fazer tricô. Cozinhar não era recomendado, pois era considerado um ofício humilde. As casas, repletas de enfeites de cristal e bibelôs de porcelana, lustres de Veneza e tapetes persas. A mulher era um elemento decorativo e deveria mostrar sua educação e civilidade nas festas e bailes, a maior parte em casas de famílias. Não tinha a necessidade de trabalhar. Uma exceção é a personagem Ariana do romance "Foi o destino", que exercia a profissão de advogada, mas que, ainda assim, no final torna-se "rainha do lar", dedicando-se às ocupações femininas. Sobre a leitura, tutores, padres e maridos selecionavam o que elas deveriam ler, sob constante vigilância. Já os heróis, garbosos e viris, dedicavam-se a atividades como literatura e arqueologia.

Destina-se a fazer referência à professora, considerada única ocupação séria para aquelas "desprovidas de fortuna". A ocupação exigia "dons naturais", modéstia, discrição e austeridade no vestir, "aspecto sofrido", como evidencia Guacira Lopes Louro (ano). Nenhuma heroína de M. Delly exerceu o magistério. O simples desejo de lecionar, nos romances, aparece como motivo de desaprovação. No romance "Magali", inclusive, a personagem ouve a seguinte frase: "Você é bonita demais para fazer-se professora" (Magali, p. 107 apud Cunha, p. 96).

Sobre a sexualidade, estava sempre presa aos limites, o corpo era pouco mencionado. Tratava-se de um erotismo feito de insinuações, olhares lânguidos, seios arfantes e frêmitos intensos. A virtude maior era a caridade, sendo comum que o marido destinasse à esposa um valor, geralmente em dinheiro, para que ela se dedicasse a atividades dessa natureza.

"Livros educam / seduzem, pois entre as letras e seus silêncios pode-se ir muito mais longe". (ibidem, p. 104). 


\section{M. Delly alimenta a imaginação: Nobres, Ricas e Felizes}

Relata-se, neste capítulo, todo o encantamento apresentado pelo livro, aproximando as narrativas do clima dos contos de fadas, desde as capas e os títulos, até as histórias propriamente ditas. Muitas histórias se passavam na França e privilegiavam valores e comportamentos vigentes na Europa dos séculos XIX e XX.

Observa-se a imprecisão temporal, característica dos contos de fadas, também nestas obras analisadas, bem como o encantamento pelos cenários, aparecendo constantemente castelos e jardins idílicos, nos quais a vida se desenrolava; havia também exageradas descrições desses lugares e situações, para que a história fosse ricamente envolvente.

As heroínas na maioria das vezes apareciam como mulheres frágeis, vítimas, inocentes, chorosas, acreditando sempre que alguém as salvaria. Quanto aos heróis, eram quase sempre descritos como príncipes, duques, pessoas da aristocracia, ou homens de grande prestígio social.

Assinala-se também que, assim como nos contos de fadas, nos romances de M. Delly, há a presença de elementos fantásticos, como por exemplo, em "Magali", em que a personagem principal é acometida de um sono profundo, provocado por um misterioso perfume inalado.

Quanto às roupas, as descrições também mexiam com o imaginário das leitoras, suscitando desejos: trajes de sedas e crepes, "vaporosos e diáfanos" (ibidem, p. 114), por seu alto valor, estiveram sempre ligados à nobreza e a classes abastadas; chapéus, bolsas, luvas, chales, descritos em igual proporção. Essas peças do vestuário sugeriam, segundo Maria Teresa, inadequação para o trabalho. Do mesmo modo, as cores indicavam leveza e pureza; tons claros eram os mais correntes, desde o rosa ao azul celeste, creme, pérola, verde-claro, mas o malva foi destacado por Maria Teresa, que ocorre em muitas de suas citações em vários livros, e também, por caracterizar uma imprecisão em sua definição, dando ideia de "impossíveis de serem definidas" (ibidem, p. 115). Essa indefinição também foi sentida pelas entrevistadas, quando foram levadas a explicar o que seria a cor "malva" para elas. E, como o esperado, cada uma tinha a explicação para a malva, "a sua malva".

Outra característica observada é sobre os parques, em que se nota uma "natureza luxuriante" (ibidem, p. 117), remetendo, como no demais, ao romantismo, sugerindo fantasias celestes e momentos de tranquilidade.

Ao descrever esses cenários, trajes, objetos luxuosos, a autora procurou ilustrar o modo como estes romances alimentaram o imaginário das leitoras. "As leitoras podiam se surpreender, estranhar ou mesmo sentir repulsa pelo que liam, mas tudo indica que também eram inevitavelmente 'educadas' e 'seduzidas' pela intensidade da fantasia que cintilava em cada palavra" (ibidem, p. 121). 


\section{Depois do Último Capítulo}

Maria Teresa apresenta, momentaneamente, na ideia de conclusão, o ato de "guardar", seu objeto de estudo. Guardar não no sentido de esconder ou trancar, mas de abrir-se a novas possibilidades de leitura e interpretação, considerando a sua leitura do objeto como "uma oferta de feixes possíveis - tecido aberto e inconcluso de conhecimentos e impressões". (ibidem, p. 125).

Após retomar as ideias presentes em toda a sua produção, a autora nos brinda com uma reflexão sobre os "herdeiros" deixados por estes romances - as coleções atuais, mais apimentadas e compatíveis com nosso tempo, tais como "Sabrina", "Bianca", "Júlia" e outras novelas atuais, além de alguns questionamentos interessantes: "O conceito de felicidade foi se modificando ou adquiriu nova roupagem? Os folhetins das novelas atuais rompem com o ideal de felicidade do romance folhetim dos anos 30 a 60 ? O que povoa o imaginário da professora primária dos anos 90?” (ibidem, p. 129).

Perguntas que, segundo Maria Teresa, persistem. Cabe a nós, leitores dessa obra, com nossas práticas criadoras, transformá-las com nossos sentidos singulares.

\section{Considerações Finais}

As relações que podemos estabelecer com "Armadilhas da sedução: os romances de M. Delly" são quanto ao percurso metodológico, que nos auxilia no fortalecimento de que uma pesquisa com obras literárias no campo da Educação é possível e mais do que válida, é necessária para que possamos entender a formação de subjetividades (ou processos de subjetivação).

Dentre o referencial teórico utilizado em nossas pesquisas em andamento, que podem nos remeter à obra de Maria Teresa S. Cunha, estão aportes da história cultural, tendo Chartier e Certeau como autores chaves, além de estudos da linguagem, com Rancière, Foucault e Bakhtin, que entendem a escrita enquanto processo na totalidade de sua relação entre locutor/autor-palavra (falada/escrita) - ouvinte/leitor, bem como suas relações com o campo da arte. Larrosa, em sua perspectiva de "experiência de leitura" / formação, contribui para os estudos que vêm sendo desenvolvidos. Estudos, a partir da perspectiva dos escritos autobiográficos, também contribuem para nossas propostas, tais como os apresentados em Camargo (2010).

Indicamos a existência de trabalhos sobre traduções, análises literárias e/ou voltadas para uma contextualização histórica da obra e algumas experiências de leitura em ambientes escolares e não-escolares. Destacamos uma grande produção acadêmica voltada para o tema da "formatação" (como a obra que molda comportamentos) e poucas produções quanto à humanização. 


\section{Referências}

BAKHTIN, M. Estética da criação verbal. 4 ed. São Paulo: Martins Fontes, 2003.

BOGDAN, R. C.; BIKLEN, S. K. Investigação qualitativa em educação: uma introdução à teoria e aos métodos. Tradução de Maria João Alvarez, Sara Bahia dos Santos e Telmo Mourinho Baptista. Porto: Porto Editora, 1994. (Colecção Ciências da Educação).

CAMARGO, M. R. R. M. de (org.); SANTOS, Vivian C.C. (colab.) Leitura e escrita como espaços autobiográficos de formação. São Paulo: Cultura Acadêmica, 2010.

CERTEAU, M. de. A invenção do cotidiano - artes de fazer. Petrópolis: Vozes, 1998.

CHARTIER, R. O mundo como representação. Estudos Avançados, São Paulo, v. 11, n. 5, p. 173-191, 1991.

FOUCAULT, M. A linguagem ao infinito. In: Ditos e escritos III - Estética: Literatura e Pintura, Música e Cinema. Rio de Janeiro: Forense Universitária, 2006b. pp.47-59.

RANCIÈRE, J. O mestre ignorante - cinco lições sobre a emancipação intelectual. Tradução de Lilian do Valle. Belo Horizonte: Autêntica, 2002.

Recebido em: 30/07/2015

Aprovado para publicação em: 20/04/2016

Publicado em: 30/04/2016 